\title{
Strategies for Prevention of Delayed Ettringite Formation in large Concrete Sections
}

\author{
K. Myuran, N.S.A. Wanigaratne and M.T.R. Jayasinghe
}

\begin{abstract}
With many large scale civil engineering construction projects being undertaken, there is a possibility to find large concrete pours in thick members. Due to the hydration process, temperatures in concrete will increase during early stages and when the temperature exceeds $70^{\circ} \mathrm{C}$, Delayed Ettringite Formation (DEF) can take place. DEF can have adverse long term effects when moisture is present leading to severe cracking of the concrete as it ages. Thus the key to prevent DEF is to control the maximum temperature that concrete could reach during early stages . Mineral additives like fly ash can play a major role in this regard. This paper presents several strategies to mitigate DEF, including the selection of limiting values for member thicknesses that could be cast with different mixes and grades of concrete in different climatic regions in Sri Lanka.
\end{abstract}

Keywords: Delayed ettringite formation, Fly ash

\section{Introduction}

With many large scale construction activities taking place in Sri Lanka, the use of concrete has increased to a significant level. Generally, higher strengths like Grades 30, 35, 40 or more are used in special cases such as in water retaining structures, pre stressed concrete members, etc. The use of such higher strengths like Grades 30, 35 and 40 for reinforced concrete is becoming a common practice. When concrete is used in large structures, there is a tendency for temperature to rise to a very high level within the structure itself during the first 30 hours of its concreting [1]. The increase in temperature due to the heat of hydration depends on many factors. The key factor among them is the grade of concrete that could have a direct influence on the amount of cement available. The type of formwork, i.e plywood, steel etc., also could have some effect on structures like walls if the thickness is not substantial [1]. On structures like ground slabs or large pile caps, the top surface that is exposed to the atmosphere can facilitate the loss of a portion of the heat. The ground also could facilitate the loss of heat to a certain extent. In concrete works with large thicknesses, such as pile caps of $2.0 \mathrm{~m}$ thickness, it is still possible to have the core region to reach high temperatures, where at times it could even exceed $70^{\circ} \mathrm{C}$, despite the loss of heat through both the top and the bottom surfaces. Similar high temperatures can be expected in thick reinforced concrete walls cast with concrete of high strength.
When the temperature of concrete exceeds $70^{\circ} \mathrm{C}$, there is a possibility for a sequence of chemical reactions to take place that can lead to Delayed Ettringite Formation (DEF), which in turn can have adverse long term effects. This paper deals with DEF and the measures that can be taken for its mitigation.

\section{Objectives}

The main objective of this research is to find out the likelihood of DEF in different grades of concrete and to propose suitable actions for its mitigation.

\section{Methodology}

The following methodology was used:

- Field temperature measurements were obtained from the actual construction activities to assess the maximum temperatures within large concrete pours and also to validate the software used for predicting the peak temperatures.

- The validated software was used to

K. Myuran, B.Sc.Eng Hons(Moratuwa), Temporary Instructor, Department of Civil Engineering, University of Moratuwa.

N.S.A. Wanigaratne, B.Sc.Eng, P.G.Dip., C.Eng, MIE(Sri Lanka), MSSE (SL), Chief EngineerDesigns, Maga Engineering (Pvt) Ltd.

Eng. (Prof.) M.T.R. Jayasinghe, B.Sc.Eng (Moratuwa), PhD. (Cambridge), C.Eng., MIE(Sri Lanka), Senior Professor, Department of Civil Engineering, University of Moratuwa 
predict the peak temperatures for a range of concrete grades placed in different climatic zones of Sri Lanka.

- The above results were analysed and presented in tabular and graphical forms so that an assessment of likely peak temperatures could be made prior to concreting and the necessary remedial actions taken to minimize the risk of DEF occurring.

\section{Delayed Ettringite Formation}

Delayed Ettringite Formation (DEF) can be encountered in large scale elements in which the heat of hydration leads to initial temperatures in excess of $70^{\circ} \mathrm{C}[2,3]$. DEF is a reaction that can potentially affect cementitious material causing them to swell and crack in the presence of moisture.

Ettringite is hydrated calcium trisulphoaluminate $\mathrm{Ca}_{6} \mathrm{Al}_{2}\left[\mathrm{SO}_{4}\right]_{3}[\mathrm{OH}]_{12}\left[\mathrm{H}_{2} \mathrm{O}\right]_{26}$. High temperatures alter the sulphate equilibrium between sulphate hydrates and hydrated calcium silicates (C-S-H) where reversible ion absorption onto the surface of $\mathrm{C}$ $\mathrm{S}-\mathrm{H}$ will take place. This leads to the formation of hydrated calcium monosulphoaluminate $\mathrm{Ca}_{4} \mathrm{Al}_{2}\left[\mathrm{SO}_{4}\right][\mathrm{OH}]_{12}\left[\mathrm{H}_{2} \mathrm{O}\right]_{6}$ within the concrete [4]. As the concrete cools down, the calcium, the aluminates and the sulphates of monosulphoaluminate react with the sulphates already available in the concrete leading to the formation of ettringite. Since ettringite formed subsequently in hardened concrete would occupy a larger volume, it could generate considerable stresses within the concrete leading to micro cracking which will propagate in a complex manner under moist conditions.

\section{Mineral additives and their use}

Mineral additives also known as supplementary cementitious material, can be identified as silica fume, ground granulated blast-furnace slag (GGBS) and fly ash (FA). These can generally improve the engineering properties of concrete when used for the partial replacement of cement [4]. Out of these, the most commonly available and most cost effective mineral additive used in Sri Lanka is FA. Use of FA can give desirable properties such as improved workability, reduction in the heat of hydration and a reduction in the associated thermal cracking at early ages [1]. Its presence can improve some properties associated with durability such as abrasion resistance [5] and resistance to $\mathrm{Cl}-$ ion penetration $[6,7]$. FA can also be used in self compacting concrete [4].

FA in concrete can have pozzolanic, microaggregate and morphologic effects [8]. The pozzolanic effect is due to $\mathrm{Al}_{2} \mathrm{O}_{3}$ and $\mathrm{SiO}_{2}$ in FA that can be activated by $\mathrm{Ca}(\mathrm{OH})_{2}$ produced during the heat of hydration of cement. This reaction will produce more hydrated gel over a long period of time, which will fill the capillary pores in concrete. Hence it could contribute to the strength of concrete. Therefore FA can be used to replace a part of the cement.

The microaggregate and morphologic effects also have positive effects by producing dense concrete. The microaggregate effect is due to microbeads in FA that can disperse in concrete and combine with the gel produced as a result of hydration producing a dense concrete. The morphologic effect is due to microbeads in FA working as 'Lubricating balls' thus improving the workability of fresh concrete.

Hence, FA can be considered as a material with many benefits and having also the ability to replace part of the cement in concrete. It can certainly assist in controlling the peak temperatures. There are two classes of FA available. ASTM Class F type FA is considered as low-calcium FA. The other is ASTM Class C that is considered as high-calcium fly ash [8]. The type of FA depends on the type of coal burnt to generate energy. Class $\mathrm{F}$ is produced by burning anthracite or bituminous coal. Burning of lignite or sub-bituminous coal will result in class $C$. In Sri Lanka, class $F$ type is commonly available. In class $\mathrm{F}, \mathrm{CaO}$ content would be less than $20 \%$ and in Class C it would be more than 20\%. Thus Class $\mathrm{F}$ requires $\mathrm{Ca}(\mathrm{OH})_{2}$ to form strength-developing products in the concrete. Hence it is suitable only for the partial replacement of cement. This percentage is generally limited to $25 \%$ in Sri Lanka. However, a higher percentage could be used if detailed studies with different mixes are used to predict the strength development characteristics.

\section{Prediction of peak temperature}

The peak temperature reached by a concrete will depend on the concrete placing temperature, the amount of cement in the concrete, the thickness of the section and the type of formwork used [1].

For the peak temperature produced, the amount of cement in the concrete could be a critical parameter. Since concrete will not be 
kept under steady state conditions, the peak temperature has to be determined using suitable software that can accurately take account of the heat transfer or use actual measurements. Such spreadsheet based software is available with CIRIA publication No C660. This program has been calibrated in Singapore for tropical conditions with research where the placing temperature is varied from $7^{\circ} \mathrm{C}$ to $32^{\circ} \mathrm{C}$ [1]. The typical output is given in Appendix A. The determination of peak temperature with actual measurements is an expensive and time consuming process and hence will not be practically possible at the initial design stage. Hence the use of software can be fully justified although it may have some margin of error.

This software has been written for ordinary Portland Cement (identified as CEM1 42.5 in Europe) and it can accommodate GGBS and FA on a percentage basis. In this study, this computer program has been used after further validation with actual measurements taken in Sri Lanka. The relevant calibration results are given in Appendix B. The calibrations carried out in Sri Lanka with a few case studies have revealed that the predicted values for the peak temperatures are reasonably accurate. When predicting the values for different cases, the density of concrete was taken as $2450 \mathrm{~kg} / \mathrm{m}^{3}$ and the specific heat of concrete was considered to be between 1.01 to $1.04 \mathrm{~kJ} / \mathrm{kg}$.K depending on the cement content and water cement ratio. As indicated in Table B.3 of Appendix B, there could be an error of up to $+3.5^{\circ} \mathrm{C}$ in the predicted values when compared with the actual values.

\section{Concrete mixes}

The aim of the study is to determine the probable values of peak temperatures for various grades of concrete under different climatic conditions available in Sri Lanka. Concrete mixes have been considered for Grades C25, C30, C35 and C40. In a concrete mix, the cement content and aggregate content are the parameters that could have a direct effect on the peak temperatures reached. The important parameters considered are as follows:

1. Cement is considered as ordinary Portland Cement

2. The aggregate is considered to have a specific heat of $0.8 \mathrm{~kJ} / \mathrm{kg}$.K which is typical for granite and gneiss type coarse aggregate that is generally used in Sri Lanka.
For this study, various concrete mixes were identified on the basis of their cement content as given in Table 1. This will allow a greater flexibility as indicated below:

1. When water reducing admixtures or superplasticizers are not used, the water content will be in the range of $195-200 \mathrm{~kg} / \mathrm{m}^{3}$.

2. When admixtures are available, the water content will be in the range of 160-165 $\mathrm{kg} / \mathrm{m}^{3}$.

3. The ratio between the weight of coarse and that of fine aggregates will be 1.5 or more. The coarse aggregates will be similar to the granite type and the fine aggregate will be sand.

4. The amount of FA can be in the range of $5 \%$ to $25 \%$. When the FA content is more than $20 \%$, the total binder content (cement + FA) could be increased by about $25 \mathrm{~kg} / \mathrm{m}^{3}$. However this has not been considered when preparing the guidelines. Instead, two different cement contents have been considered for each grade of concrete as indicated in Table 1. For example, for Grade 30 concrete, two cement contents, i.e 325 and $350 \mathrm{~kg} / \mathrm{m}^{3}$ have been used.

Table 1 - Cement content considered for various Grades of concrete.

\begin{tabular}{|c|c|c|c|c|}
\hline Grade & C25 & C30 & C35 & C40 \\
\hline $\begin{array}{c}\text { Cement content } \\
{\left[\mathrm{kg} / \mathrm{m}^{3}\right]}\end{array}$ & 300 & 350 & 400 & 450 \\
\cline { 2 - 5 } & 275 & 325 & 375 & 425 \\
\hline
\end{tabular}

5. Two other important parameters that can affect the peak temperature are the specific heat and the thermal conductivity. Specific heat is influenced by the type of the coarse aggregate and the water content. Appropriate values have been obtained from the guidelines given in CIRIA C660 where they are presented in a chart. It is presented in Appendix C. The specific heat value can vary between 0.97 and 1.07 $\mathrm{kJ} / \mathrm{kg} . \mathrm{K}$. For the preparation of the chart, a single value of $1.04 \mathrm{~kJ} / \mathrm{kg} . \mathrm{K}$ has been used. The thermal conductivity is considered as $2.0 \mathrm{~W} / \mathrm{m}^{2} \mathrm{~K}$ for granite type aggregate and sand as the fine aggregate.

\section{Studies related to local climates}

The method used for the calculation of the peak temperatures is expected to give conservative values [1]. The calibration carried out in Sri Lanka with few studies has revealed that the predicted values are reasonably accurate and conservative. Therefore a detailed study was 
carried out for various climatic conditions that are encountered in Sri Lanka.

Sri Lanka, being a country located close to the equator and having central hills, can have various climatic conditions that can make the concrete placing temperature to be in excess of $30^{\circ} \mathrm{C}$. Therefore, a representative sample was selected as given in Table 2 .

The effects of the following parameters have been considered for different climatic zones:

1. Placing temperature

2. Cement content

3. Formwork removal time

4. Section thickness

\subsection{Effect of the placing temperature}

In order to determine the effect of the placing temperature, Grade 30 concrete was considered. Table 3 gives the peak temperatures predicted with the software when using plywood and steel formwork with the cement content maintained at $325 \mathrm{~kg} / \mathrm{m}^{3}$ and using water reducing admixture/superplasticizer to control the water cement ratio (FA has not been used). Steel formwork can allow a greater degree of heat dissipation than plywood formwork. It can be seen that the peak temperature closely follows the placing temperature with plywood formwork. The values in brackets indicate the difference between the placing temperature and the peak

In Table 3, it is also possible to note that for thicker sections (about $2500 \mathrm{~mm}$ ), the type of formwork irrespective of whether it is steel or plywood, will not make a notable difference. The reason is that the thick core area will dominate the peak temperature and hence the heat loss from the surface would not have a significant effect.

\subsection{Effect of the cement content}

Cement is the parameter that contributes to heat generation. Therefore use of lower quantity of cement would be beneficial if the required strength can be achieved. Nevertheless, the cement content has to satisfy a certain minimum value due to durability concerns. For example, BS 8110 : Part 1: 1985 [9] specifies a minimum cement content of 275 $\mathrm{kg} / \mathrm{m}^{3}$ for Grade C30 concrete. It is $325 \mathrm{~kg} / \mathrm{m}^{3}$ and $350 \mathrm{~kg} / \mathrm{m}^{3}$ for Grade C35 and C40 respectively.

Table 2 - Placing temperatures considered for different climatic zones

\begin{tabular}{lcccc}
\hline Identification & Daily Max & Daily Mean & Daily Min & Placing temperature \\
\hline Wet zone & 30 & 27 & 24 & $30 \& 32$ \\
\hline Dry zone & 32 & 28 & 24 & $32 \& 34$ \\
\hline Altitude above $400 \mathrm{~m}$ & 27 & 24 & 21 & $27 \& 29$ \\
\hline Altitude above $800 \mathrm{~m}$ & 25 & 22 & 19 & $25 \& 27$ \\
\hline
\end{tabular}

Table 3 - Peak temperatures of $1000 \mathrm{~mm}$ and $2500 \mathrm{~mm}$ thick concrete for various placing temperatures and types of formwork in walls

\begin{tabular}{|c|c|c|c|c|}
\hline \multirow{2}{*}{$\begin{array}{l}\text { Placing temperature } \\
\qquad\left({ }^{\circ} \mathrm{C}\right)\end{array}$} & \multicolumn{2}{|c|}{$\begin{array}{l}\text { Peak temperature of } 1000 \mathrm{~mm} \text { thick } \\
\text { concrete }\end{array}$} & \multicolumn{2}{|c|}{$\begin{array}{l}\text { Peak temperature of } 2500 \mathrm{~mm} \text { thick } \\
\text { concrete }\end{array}$} \\
\hline & Plywood** & Steel*** & Plywood** & Steel*** \\
\hline 25 & 64 (39) * & $62(37)$ * & $70(45)$ * & $70(45)$ * \\
\hline 27 & $67(40) *$ & $65(38)$ * & $72(45)$ * & $72(45)$ * \\
\hline 29 & $69(40)$ * & $67(38)$ * & $74(45)$ * & $73(44) *$ \\
\hline 30 & $70(40)$ * & $69(39)$ * & $74(44)$ * & $74(44) *$ \\
\hline 32 & $72(40) *$ & $71(39)$ * & $76(44)$ * & $76(44) *$ \\
\hline 34 & $74(40)$ * & $73(39)$ * & $78(44)$ * & $78(44) *$ \\
\hline
\end{tabular}


According to Table A5 of BS 8500-1 : 2006 [10] which complies with the Euro codes, it is possible to use a minimum binder content of $260 \mathrm{~kg} / \mathrm{m}^{3}$ with $\mathrm{FA}$ as one of the mineral additives for Grade C30. Therefore, the minimum cement contents of BS 8100: Part 1: 1985 have been considered as the minimum binder content for this study.

Another parameter that would be closely associated with the cement content is the water content. The water content can be adjusted with the use of admixtures. As shown in Figure C.1 of Appendix C, a reduced water content would be advantageous since it can increase the specific heat by increasing the density of concrete and thereby marginally reducing the peak temperature. Therefore, the use of water reducing admixtures or super-plasticizers can be encouraged. It will be a good strategy to achieve the required strength while keeping the cement content as low as possible.

\subsection{Effect of formwork removal time}

Formwork removal time is important for walls. When Plywood formwork is used, the formwork can be removed generally after 24 hours. However plywood formwork can act as a good insulator and hence can assist in reducing the temperature difference between the core and the outer concrete. The early removal of formwork will facilitate a greater loss of heat. However it can increase the difference in temperatures between the core and the outer skin which may induce cracks temporarily on the outer skin of the concrete. Hence some judgement would be needed when deciding on the formwork removal time.

\subsection{Effect of section thickness}

In most large concrete members, it is possible to identify the smallest dimension. The heat loss occurs predominantly along the direction of the smallest dimension. The software has been written considering this condition with unidirectional heat flow. The heat loss in the other directions will be advantageous in situations like pile caps since it could assist in reducing the peak temperature marginally. In reinforced concrete walls, the heat flow will be primarily unidirectional.

The thickness of the section is a key parameter that can affect the peak temperature reached by a concrete wall. The effect of section thickness on the peak temperature has been obtained for different concrete mixes for the dry zone with the placing temperature at a maximum value of $32^{\circ} \mathrm{C}$. The thicknesses in excess of $500 \mathrm{~mm}$ have been selected. If the cement content is too high, even sections having less than $500 \mathrm{~mm}$ may develop peak temperatures exceeding $70^{\circ} \mathrm{C}$ which indicates that the selection of the concrete grade for a particular application may need some careful consideration by the structural designer. The results are presented in Figure 1.

According to Figure 1, if the cement content is $275 \mathrm{~kg} / \mathrm{m}^{3}$, it is possible to have a section thickness of even $3000 \mathrm{~mm}$ while maintaining the peak temperature below $70^{\circ} \mathrm{C}$. However, when the cement content is higher, for example $350 \mathrm{~kg} / \mathrm{m}^{3}$, only a thickness of $600 \mathrm{~mm}$ could be cast while maintaining the temperature at the core below $70^{\circ} \mathrm{C}$. If the cement content is 325 $\mathrm{kg} / \mathrm{m}^{3}$, a $500 \mathrm{~mm}$ thick wall would reach only $66^{\circ} \mathrm{C}$ as the peak temperature. Hence a graph of this nature can give useful information for the structural designer who has to consider many factors when selecting an appropriate Grade for a large section. 


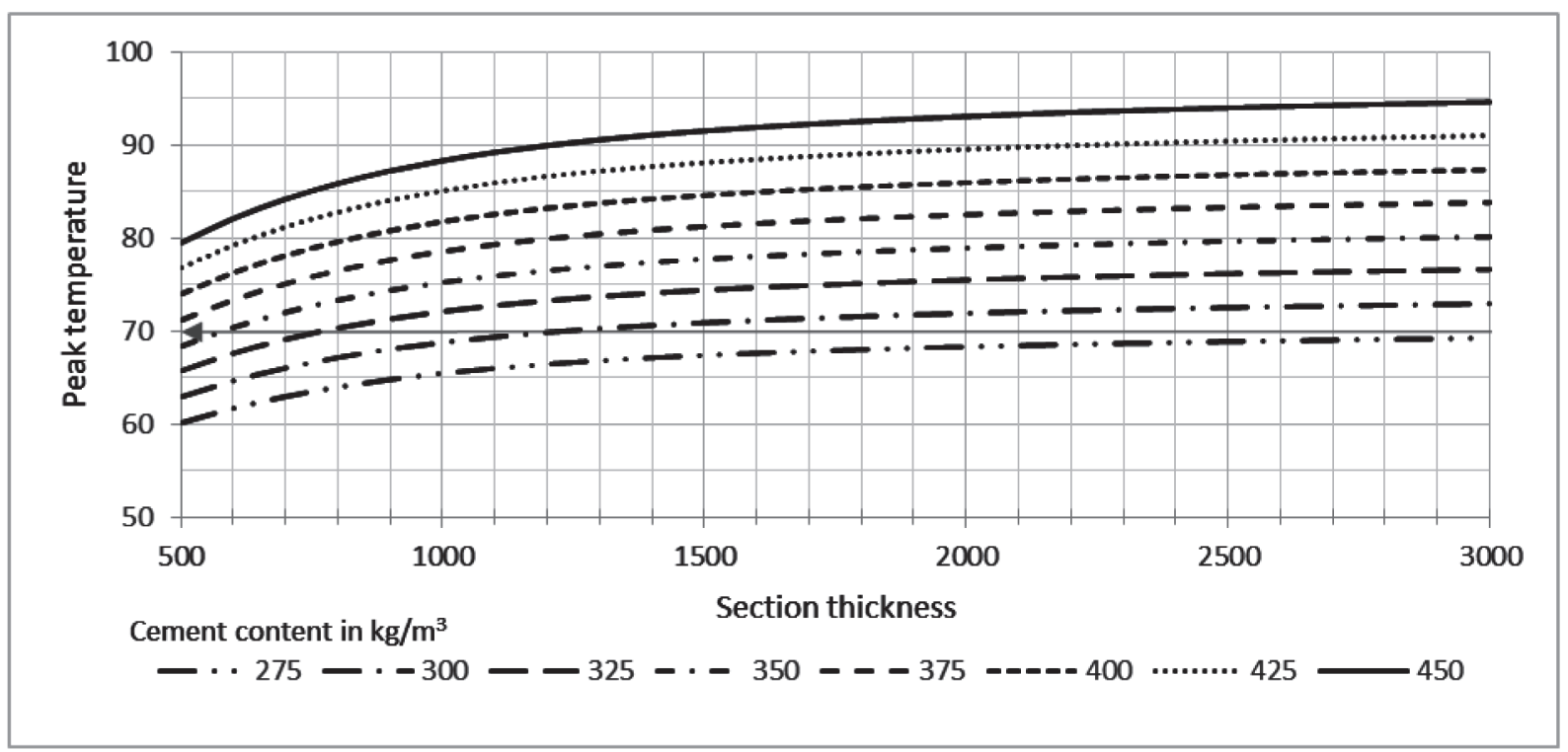

Figure 1 - Peak temperature variation of various concrete mixes with a placing temperature of $32^{\circ} \mathrm{C}$ and with $0 \%$ of Fly ash.

It is possible to obtain similar data for the above mixes provided with 5\%,10\%,15\%, 20\% and $25 \%$ of FA while maintaining a minimum binder content of $275 \mathrm{~kg} / \mathrm{m}^{3}$, for a placing temperature of $32^{\circ} \mathrm{C}$. These are presented in Figures 2 to 6 and the charts are drawn with 'Binder content' and not with 'Cement content' as FA has been used as a mineral additive. For example as can be seen in Figure 3, if the binder content is $350 \mathrm{~kg} / \mathrm{m}^{3}$ with $10 \% \mathrm{FA}$, a section up to a thickness of $850 \mathrm{~mm}$ can be cast without the risk of forming DEF at a placing temperature of $32^{\circ} \mathrm{C}$.
The same charts can be used to find out the approximate peak temperatures when there are different placing temperatures in other climatic zones. For example, if the concrete placing temperature is reduced to $28^{\circ} \mathrm{C}$, it is possible to reduce the above temperatures by $4^{\circ} \mathrm{C}$. For example, Figure 1 indicates the temperature rising to $66^{\circ} \mathrm{C}$ with $325 \mathrm{~kg} / \mathrm{m}^{3}$ of cement in a $500 \mathrm{~mm}$ thick section. The placing temperature is $32^{\circ} \mathrm{C}$. When the placing temperature is reduced to $28^{\circ} \mathrm{C}$, the peak temperature will be $62^{\circ} \mathrm{C}$. This also means that a section up to about $1500 \mathrm{~mm}$ thickness can be cast with $325 \mathrm{~kg} / \mathrm{m}^{3}$ without using FA if the placing temperature can be lowered to about $28^{\circ} \mathrm{C}$.

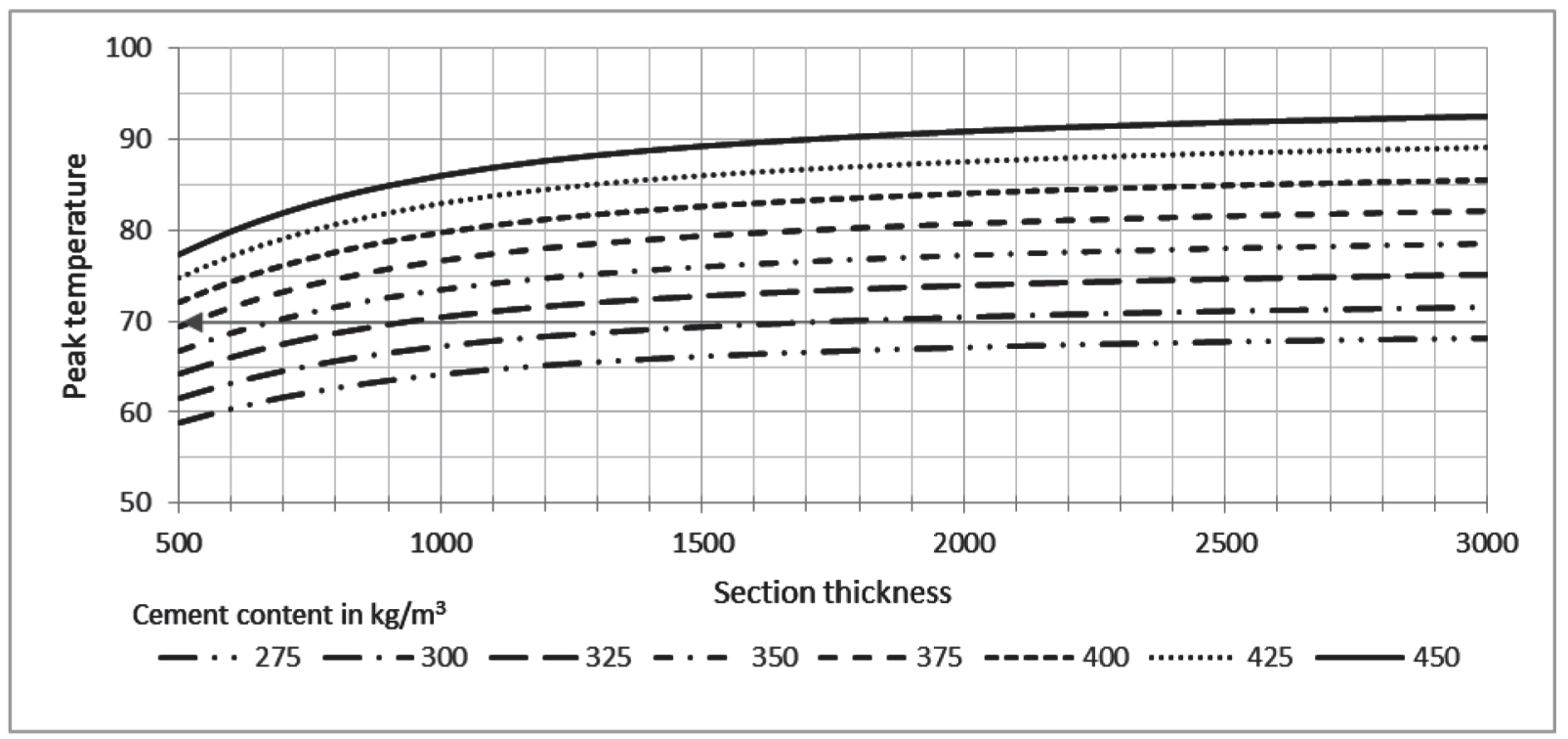

Figure 2 - Peak temperature variation of various concrete mixes with a placing temperature of $32^{\circ} \mathrm{C}$ and with $5 \%$ Fly ash. 


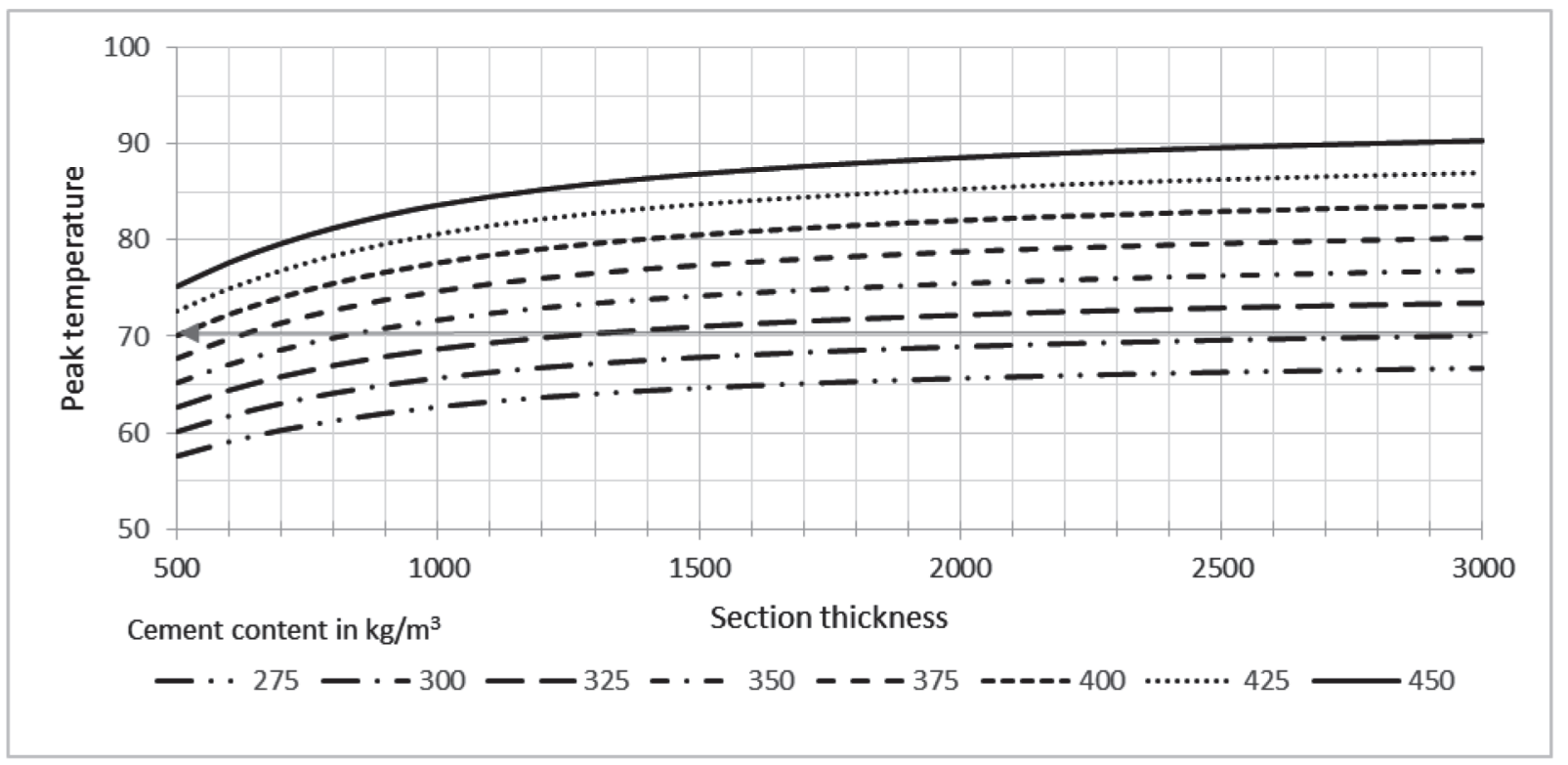

Figure 3 - Peak temperature variation of various concrete mixes with a placing temperature of $32^{\circ} \mathrm{C}$ and with $10 \%$ Fly ash.

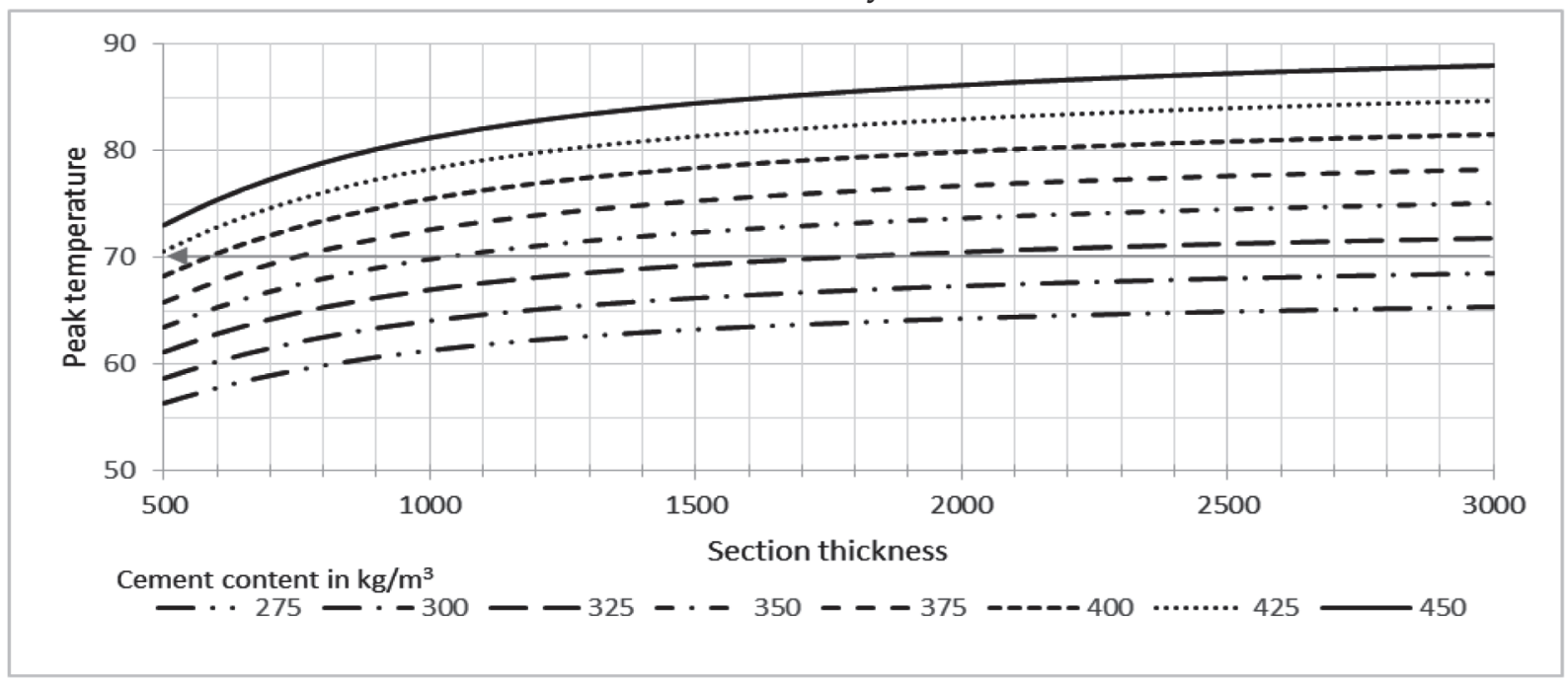

Figure 4 - Peak temperature variation of various concrete mixes with a placing temperature of $32^{\circ} \mathrm{C}$ and with $15 \%$ Fly ash.

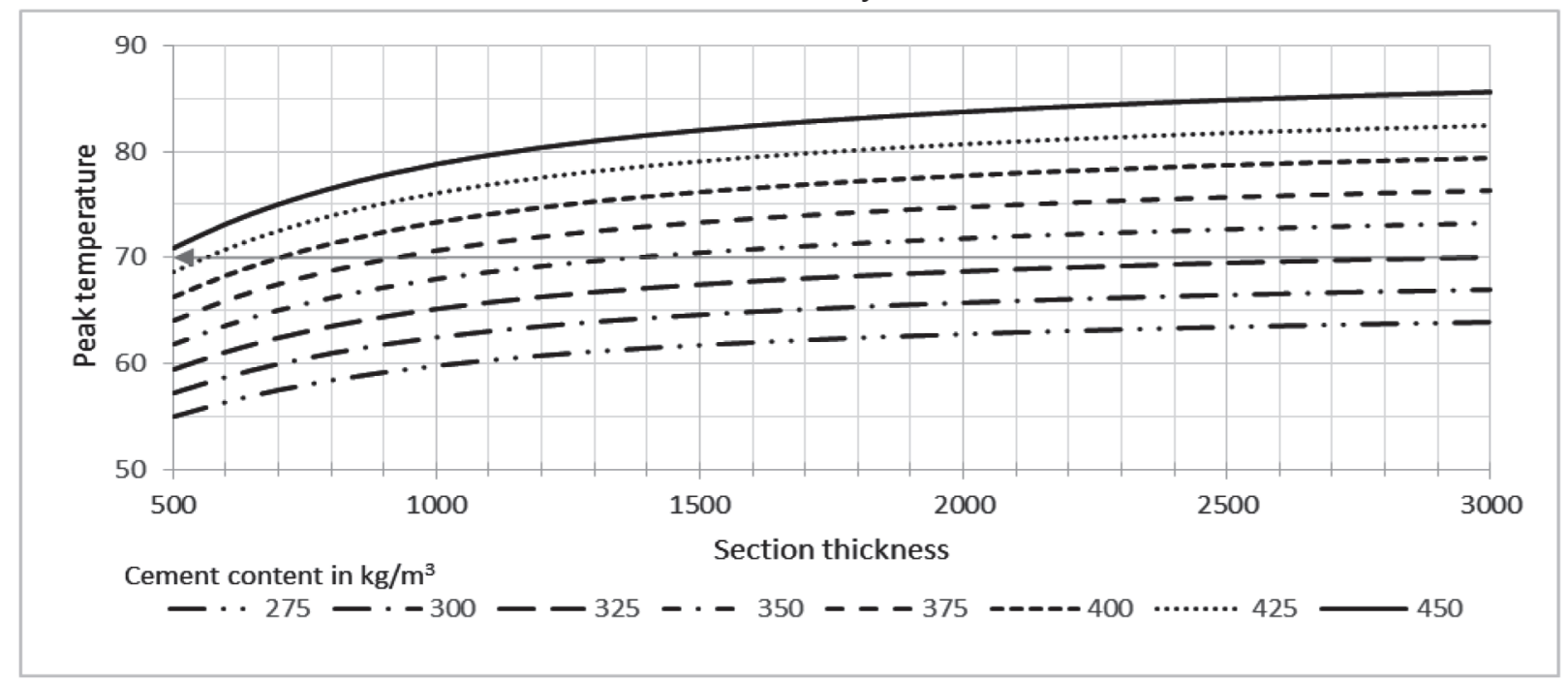

Figure 5 - Peak temperature variation of various concrete mixes with a placing temperature of $32^{\circ} \mathrm{C}$ and with $20 \%$ Fly ash. 


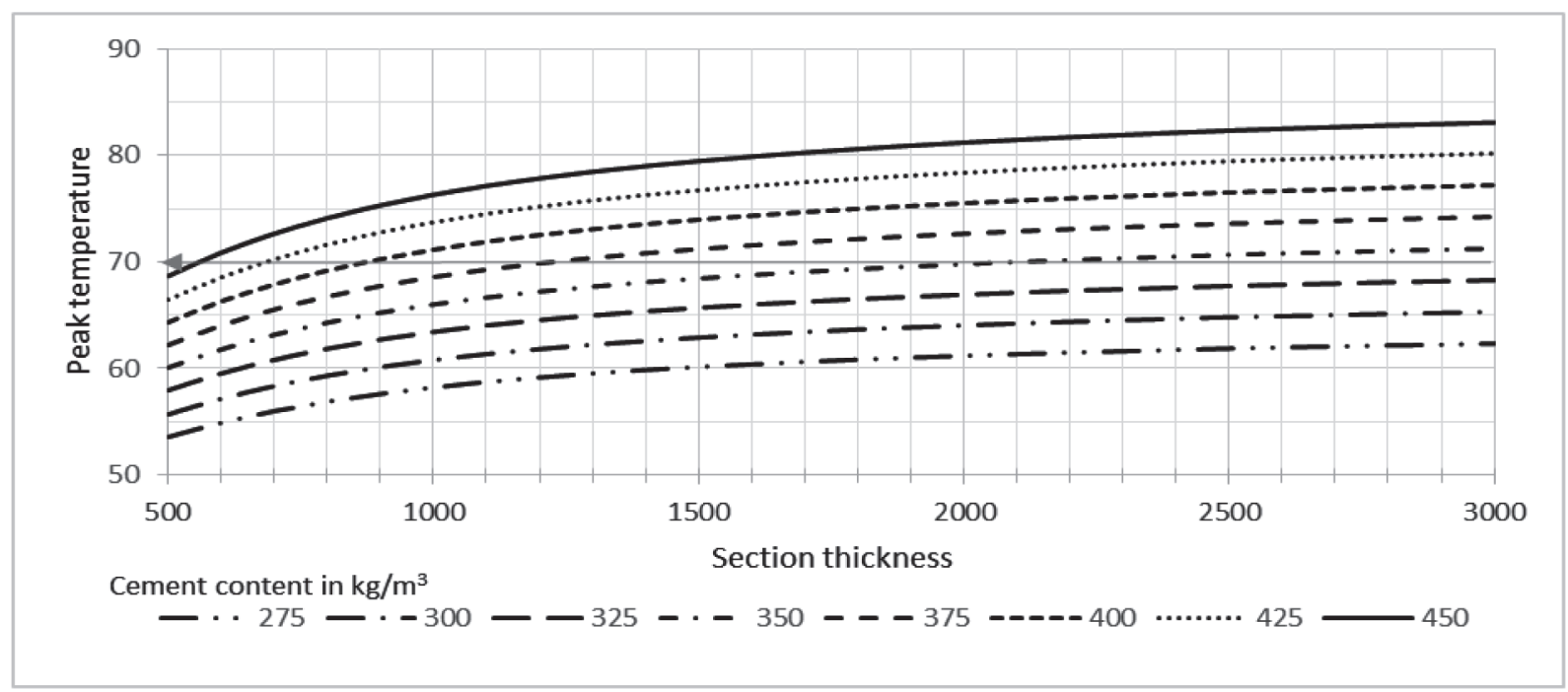

Figure 6 - Peak temperature variation of various concrete mixes with a placing temperature of $32^{\circ} \mathrm{C}$ and with $25 \%$ Fly ash.

According to Figure 6, if a stronger concrete is needed, it would be possible to use a binder content of 375 or $400 \mathrm{~kg} / \mathrm{m}^{3}$ with $25 \%$ of FA with maximum thicknesses maintained at 1200 $\mathrm{mm}$ and $900 \mathrm{~mm}$, respectively. This means that these charts can be used in many ways. One of the key applications will be for the structural designers to use these charts to find out the degree of risk involved with respect to DEF. For example, it can be stated with the data given in Figure 1 that when the cement content is about $325 \mathrm{~kg} / \mathrm{m}^{3}$, a thickness of about 750 $\mathrm{mm}$ would be safe without the use of FA and at a placing temperature of $32^{\circ} \mathrm{C}$. From Figure 4, it can be stated that when the binder content is $325 \mathrm{~kg} / \mathrm{m}^{3}$ with $15 \%$ of FA, thickness up to 1900 $\mathrm{mm}$ could be safe.

The information in Figures 1 to 6 can be summarized in one Table as given in Table 4 in which the maximum thickness for each mix with different FA contents is presented. This
Table would however be of not much use since the maximum thickness will depend on the placing temperature. It will also not allow the designer to assess the degree of risk involved. Therefore, it is recommended that Figures 1 to 6 be used for predicting the peak temperature.

\section{Other strategies to prevent DEF}

If the peak temperature cannot be controlled with the use of fly ash as a supplementary cementitious material, the other option will be to use GI pipes through which cool water can be circulated to remove part of the heat generated. However, this will be a costly operation.

Table 4 - Section thickness corresponds to a peak temperature of $70^{\circ} \mathrm{C}$ when the placing temperature is $32^{\circ} \mathrm{C}$

\begin{tabular}{lcccccccc}
\hline $\begin{array}{l}\text { Cement } \\
\begin{array}{l}\text { Content } \\
{\left[\mathrm{kg} / \mathrm{m}^{3}\right]}\end{array}\end{array}$ & 275 & 300 & 325 & 350 & 375 & 400 & 425 & 450 \\
\hline $0 \% \mathrm{FA}$ & $>3000$ & 1200 & 700 & 500 & $<500$ & $<500$ & $<500$ & $<500$ \\
\hline $5 \% \mathrm{FA}$ & $>3000$ & 1700 & 900 & 600 & $<500$ & $<500$ & $<500$ & $<500$ \\
\hline $10 \% \mathrm{FA}$ & $>3000$ & 2800 & 1200 & 800 & 600 & $<500$ & $<500$ & $<500$ \\
\hline $15 \% \mathrm{FA}$ & $>3000$ & $>3000$ & 1700 & 1000 & 700 & 500 & $<500$ & $<500$ \\
\hline $20 \% \mathrm{FA}$ & $>3000$ & $>3000$ & $>3000$ & 1300 & 900 & 700 & 500 & $<500$ \\
\hline $25 \% \mathrm{FA}$ & $>3000$ & $>3000$ & $>3000$ & 2100 & 1200 & 800 & 600 & 500 \\
\hline
\end{tabular}




\section{Conclusions}

One of the critical parameters for early heat generation is the binder content which can contain only cement or cement and mineral additives such as FA. It is shown with the peak temperatures predicted for walls that FA can be used very effectively. Therefore, it would be a challenge to obtain the required strength when the total binder content is controlled and when FA has also been used to replace part of the cement in the binder. This means that the strength specified for large sections would have to be controlled carefully. The strength specified will have to be deliberately kept at the minimum value that would be sufficient to meet the durability requirements. The selection of grades higher than the minimum needed for durability can certainly bring the concrete to the danger zone leading to DEF in thicker sections.

\section{References}

[1] Bamforth, P. B., "Early-Age Thermal Crack Control in Concrete", CIRIA C660, London, 2007.

[2] Pavoine, A., Brunetaud, X., Divet, L., "The Impact of Cement Parameters on Delayed Ettringite Formation". Cement and Concrete Composites, Volume 34, 2012, pp. 521-528.

[3] Taylor, H. F. W., Famy, C., Scrivener, K. L., "Delayed Ettringite Formation". Cement and Concrete Research, Volume 31, 2001, pp. 683-693.

[4] Hannesson, G., Kuder, K., Shogren, R., Lehman, D., "The Influence of High Volume of Fly Ash and Slag on the Compressive Strength of Self-Consolidating Concrete". Construction and Building Materials, Volume 30, 2012, pp. 161-168.

[5] Siddique, R., "Effect of Fine Aggregate Replacement with Class F fly Ash on the Abrasion Resistance of Concrete". Cement and Concrete Research, Volume 33, 2003, pp. 1877-1881.

[6] Bouzoubaâ, N., Zhang, M. H., Malhotra, V. M., "Laboratory-Produced High-Volume Fly Ash Blended Cements: Compressive
This could be contrary to the usual practice that prevails among design engineers who have the general perception that stronger concrete will be more durable and hence more desirable. This is true for thin sections. However, when thick sections are involved, it is necessary to address not only the durability related concerns, but also DEF related concerns.

The data presented in this paper have to be considered only as indicative values since the actual temperatures reached could depend on many parameters. However, having an easy reference for the design engineers on peak temperatures in large pours will be extremely useful since they will then have the flexibility to change the decisions in the early stages of their designs with respect to section sizes or grades of concrete or on the use of supplementary cementitious material.

Strength and Resistance to the Chloride-Ion Penetration of Concrete". Cement and Concrete Research, Volume 30, 2000, pp. 1037-1046.

[7] Ramezanianpour, A., "Effect of Curing on the Compressive Strength, Resistance to Chloride-Ion Penetration and Porosity of Concretes Incorporating Slag, Fly Ash or Silica Fume". Cement and Concrete Composites, Volume 17, 1995, pp. 125-133.

[8] Uysal, M., Akyuncu, V., “Durability Performance of Concrete Incorporating Class F and Class C Fly Ashes". Construction and Building Materials, Volume 34, 2012, pp. 170-178.

[9] BS 8110-1:1985, Structural Use of Concrete. Code of Practice for Design and Construction.

[10] BS 8500-1:2006+A1:2012, Concrete. Complementary British Standard to BS EN 206-1. Method of specifying and guidance for the specifier.

[11] Myers, T. G., Fowkes, N. D., Ballim, Y., "Modelling the Cooling of Concrete by Piped Water". Journal of Engineering Mechanics, 2009, pp. 1375-1383. 


\section{Appendix A. Output of thermal model software}
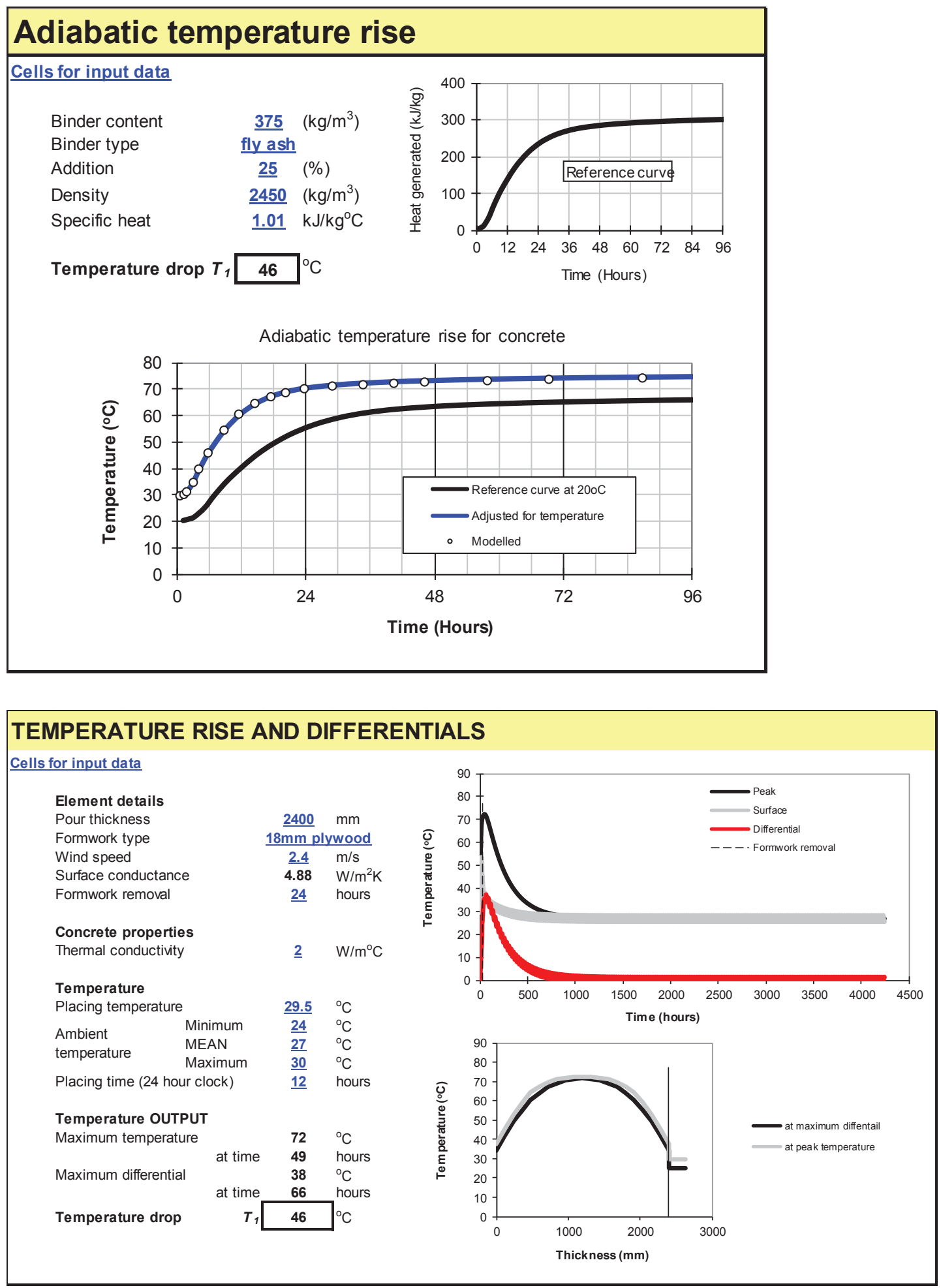


\section{Appendix B. Calibration of the thermal model}

Calibrations were carried out considering several field data taken in and around Colombo in Sri Lanka in order to check the accuracy of the thermal model used (spread sheet given in CIRIA-C660).

Temperature readings were taken for a variety of thicknesses in concrete structures such as walls, large beams and pile caps. Peak temperatures observed for those elements were compared with the values obtained from the thermal model. For example, consider a concrete mix of $375 \mathrm{~kg} / \mathrm{m}^{3}$ of binder content with a 0.5 water to cement ratio and a placing temperature of $29.5^{\circ} \mathrm{C}$. Mix proportions and the measured temperature readings with time are given in Table B.1 and Figure B.1 respectively.

Table B.1 - Mix proportion

\begin{tabular}{|l|c|}
\hline Ingredients & Amount $\left.\mathbf{( k g} / \mathbf{m}^{3}\right)$ \\
\hline Cement & 280 \\
\hline Fly ash & 95 \\
\hline Water & 187 \\
\hline Fine aggregate uncrushed & 573 \\
\hline Fine aggregate crushed & 245 \\
\hline Coarse aggregate & 1040 \\
\hline
\end{tabular}

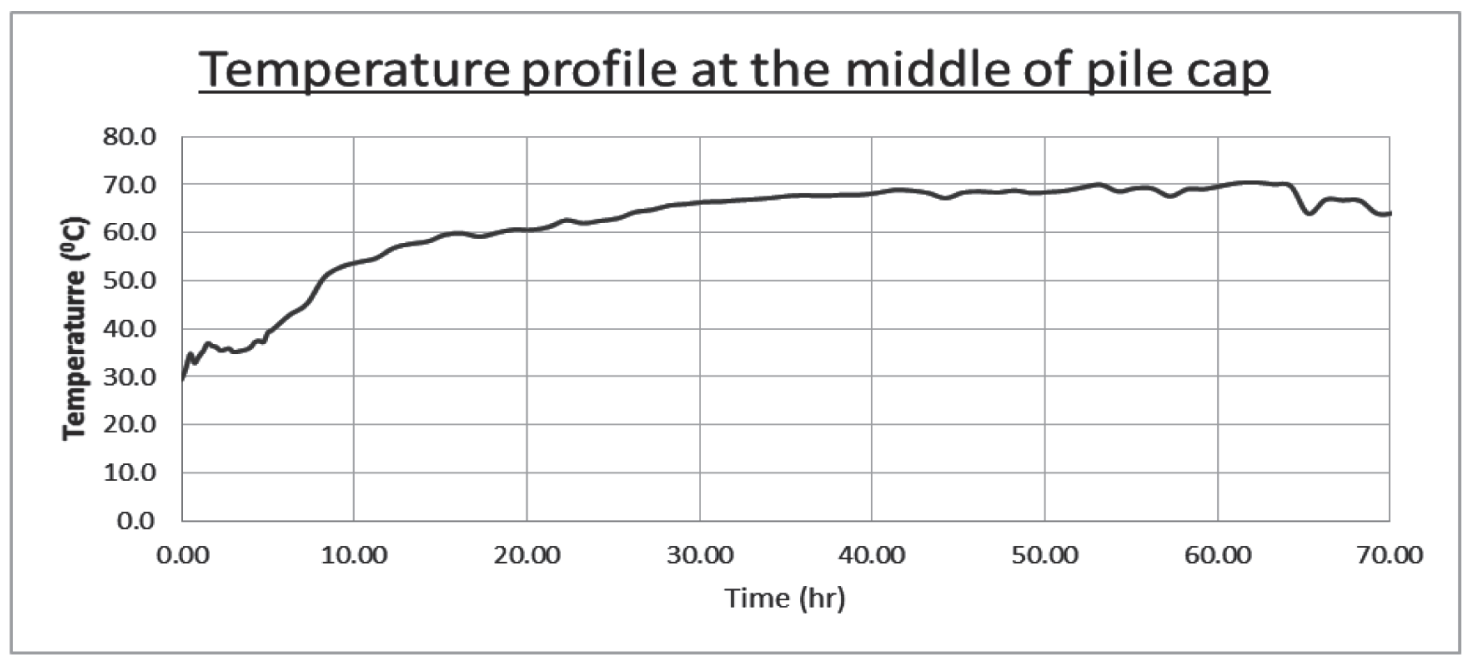

Figure B.1- Measured temperature variation at the centre of pile cap

According to Figure B.1, peak temperature at the centre of the pile cap can be found to be $70.5^{\circ} \mathrm{C}$ and the predicted value from the thermal model for the respective pile cap was $72.5^{\circ} \mathrm{C}$. The critical values used to predict the peak temperature for the model are given in Table B.2. 
Table B.2 - Values used to predict peak temperature in the thermal model

\begin{tabular}{|l|l|}
\hline Binder content & $375 \mathrm{~kg} / \mathrm{m}^{3}$ \\
\hline Binder type & fly ash \\
\hline Addition & $25 \%$ \\
\hline Density & $2400 \mathrm{~kg} / \mathrm{m}^{3}$ \\
\hline Specific heat & $1.01 \mathrm{~kJ} / \mathrm{kg} . \mathrm{K}$ \\
\hline Pour thickness & $2400 \mathrm{~mm}$ \\
\hline Placing temperature & $29.5^{\circ} \mathrm{C}$ \\
\hline
\end{tabular}

Following the above procedure, the peak temperatures measured for many walls, large beams and pile caps were verified against the respective peak temperatures predicted by the thermal model. The compared data has been summarized in Table B.3.

Table B.3 - Summarized validation data

\begin{tabular}{|c|c|c|c|c|c|c|c|c|c|c|}
\hline \& & 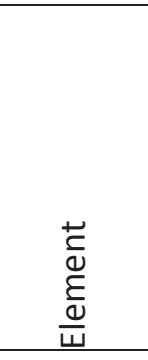 & 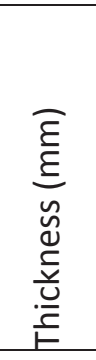 & 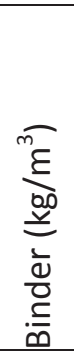 & $\begin{array}{l}\frac{1}{n} \\
\mathbb{0} \\
\geq \\
\mathbb{1} \\
4 \\
0 \\
0 \\
0\end{array}$ & $\frac{v}{3}$ & 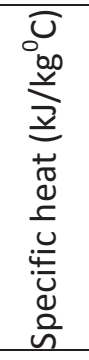 & 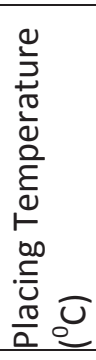 & 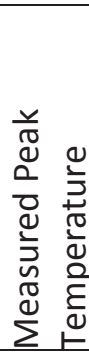 & 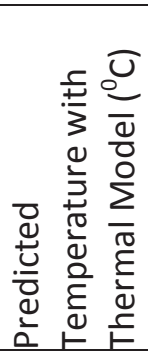 & 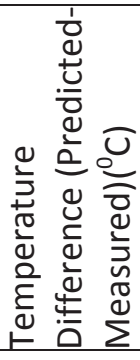 \\
\hline 1 & Wall & 1500 & 435 & 25.0 & 0.40 & 1.02 & 30.8 & 74.7 & 77.6 & 2.9 \\
\hline 2 & Wall & 500 & 400 & 25.0 & 0.40 & 1.04 & 29.6 & 70.0 & 71.8 & \\
\hline 3 & Wall & 1500 & 350 & 21.0 & 0.50 & 1.02 & 30.0 & 66.1 & 68.9 & 2.8 \\
\hline 4 & Wall & 1750 & 350 & 21.0 & 0.50 & 1.02 & 31.5 & 68.3 & 71.1 & 2.8 \\
\hline 5 & Wall & 1800 & 435 & 25.3 & 0.40 & 1.02 & 30.8 & 76.2 & 78.6 & 2.4 \\
\hline 6 & Vall & 750 & 350 & 21.0 & 0.50 & 1.02 & 30.0 & 66.9 & 69.8 & 2.9 \\
\hline 7 & Beam & 1500 & 435 & 25.3 & 0.40 & 1.02 & 30.0 & 73.2 & 76.6 & 3.4 \\
\hline 8 & Beam & 1500 & 435 & 25.3 & 0.40 & 1.02 & 29.5 & 72.9 & 76.3 & 3.4 \\
\hline 9 & Beam & 2200 & 435 & 25.3 & 0.40 & 1.02 & 30.0 & 76.6 & 79.0 & 2.4 \\
\hline 10 & Pile Cap & 2400 & 400 & 25.0 & 0.43 & 1.02 & 30.5 & 74.5 & 75.9 & 1.4 \\
\hline 11 & Pile Cap & 2400 & 400 & 25.0 & 0.43 & 1.02 & 31.0 & 75.3 & 76.3 & 1.0 \\
\hline 12 & Pile Cap & 2400 & 375 & 25.0 & 0.50 & 1.01 & 29.5 & 70.5 & 72.5 & 2.0 \\
\hline 13 & Pile Cap & 2400 & 435 & 25.0 & 0.40 & 1.02 & 30.0 & 77.2 & 79.6 & 2.4 \\
\hline 14 & Pile Cap & 2400 & 350 & 21.4 & 0.50 & 1.02 & 31.5 & 70.2 & 72.3 & 2.1 \\
\hline 15 & Pile Cap & 2400 & 435 & 25.0 & 0.40 & 1.02 & 29.0 & 75.5 & 78.7 & 3.2 \\
\hline 16 & Pile Cap & 2400 & 375 & 25.0 & 0.50 & 1.01 & 31.0 & 71.5 & 73.8 & 2.3 \\
\hline
\end{tabular}

Note: - Concrete sections have been considered as walls where height of the particular section exceeds other dimensions. 
Appendix C. Specific heat and thermal conductivity (Taken from CIRIA C 660)

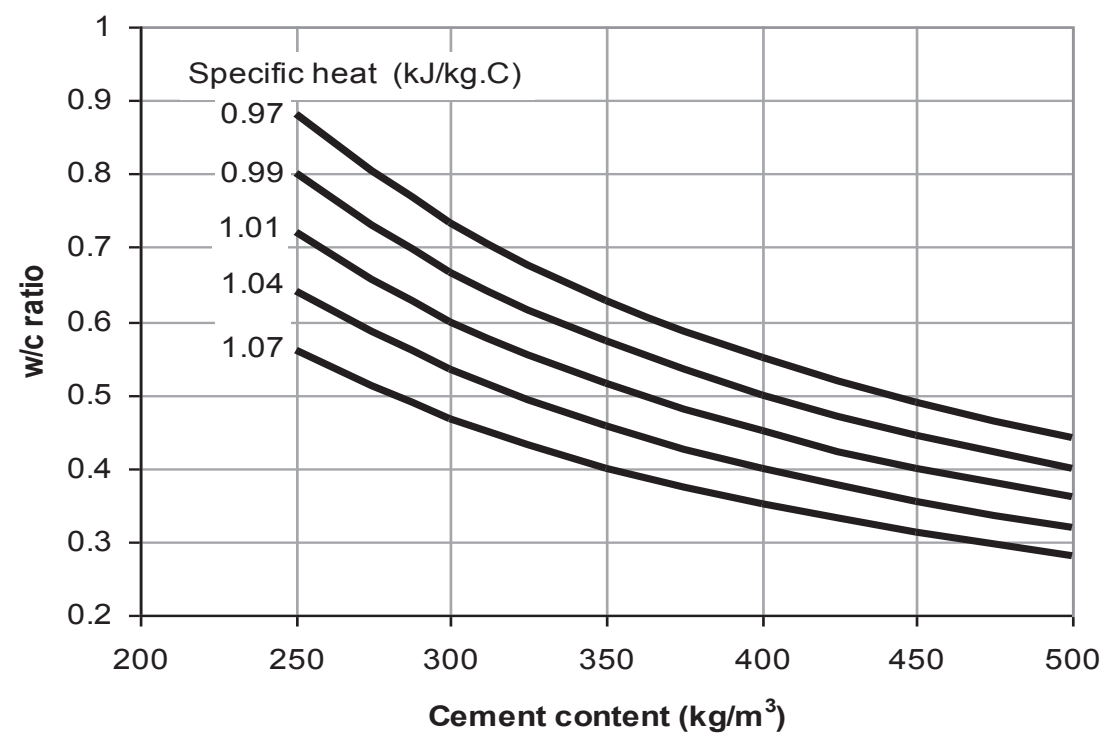

Figure C.1 - Relationship between cement content, w/c ratio and early-age specific heat (assuming the specific heat of the aggregate is $0.8 \mathrm{~kJ} / \mathrm{kg} . \mathrm{K}$ )

Note: - The values for concrete in Figure 1 should be increased by 0.8 times the change in the value for the aggregate. So for aggregate with a specific heat of $0.84 \mathrm{~kJ} / \mathrm{kg} . \mathrm{K}$, concrete with a value of 1.01 would increase by $0.8 \times(0.84-0.8)=0.032$ to be equal to $1.042 \mathrm{~kJ} / \mathrm{kg} . \mathrm{K}$.

Table C.1 - Proposed values of thermal conductivity of concrete for use in early age thermal modelling (Taken from CIRIA C 660)

\begin{tabular}{|l|c|c|}
\hline Aggregate type & \multicolumn{2}{|l|}{ Thermal conductivity of concrete (W/m.K) } \\
\hline & $\begin{array}{l}\text { Sand and aggregate from } \\
\text { same rock type }\end{array}$ & $\begin{array}{l}\text { Aggregate from defined } \\
\text { rock type with siliceous } \\
\text { sand }\end{array}$ \\
\hline $\begin{array}{l}\text { Quartzite and siliceous gravels } \\
\text { with high quartz content }\end{array}$ & 2.9 & 2.9 \\
\hline Granite, gabbros, hornfels & 1.4 & 1.9 \\
\hline Dolerite, basalt & 1.3 & 1.8 \\
\hline Limestone, sandstone, chert & 1.0 & \multicolumn{2}{|c|}{} \\
\hline
\end{tabular}

